\title{
Body composition of healthy Spanish children
}

\author{
Soledad Aguado-Henche*, Rosa Rodríguez-Torres, Asunción Bosch-Martín, Luis Gómez-Pellico
}

Human Anatomy and Embriology Department, School of Medicine, University of Alcalá, Alcalá de Henares, Madrid, Spain;

*Corresponding Author: soledad.aguado@uah.es

Received 27 January 2011; revised 5 March 2011; accepted 23 March 2011.

\begin{abstract}
This paper shows the distribution of the body compartments, and the age and gender related changes in Spanish children. Subjects and Methods: A total of 231 healthy children from Madrid (Spain) were recruited and divided into 3 groups according to age (birth-5, 6-10, 11-15y). Body compartments (fat mass, lean mass and bone mass) measures were obtained from dual energy X-ray absorptiometry (DXA) scans. Total and regional body compositions were evaluated. Results: There were gender differences for TBFM (total body fat mass) in 11 - 15 year age group and for TLBM (total lean body mass) in all age groups except for the $6-10$ year age group. TBMC (total bone mineral content) shows significant gender differences form birth. Conclusions: Contrary to boys, girls showed from early infancy a smaller proportion of muscle mass and a higher proportion of body fat (from the age of 10), with fat deposits being mostly peripheral. Bone mass and muscle mass values were higher in boys.
\end{abstract}

Keywords: Body Composition; Dual Energy X-Ray Absorptiometry; Children

\section{INTRODUCTION}

The assessment of the body composition provides information regarding the main constituents of the human body and allows differentiation between genders and ethnicities due to age, growth, physical activity, diet and disease.

Obesity, type 2 diabetes mellitus (DM) and osteoporosis are the most frequent metabolic disorders that have strong associations with body composition. Although it's certainly clear that obesity, attributable to increased adiposity, can be considered a disorder of body composition, a similar perspective applies to type $2 \mathrm{DM}$. The metabolic perturbations of type $2 \mathrm{DM}$ have been found to be associated with certain patterns of adipose tissue and fat distribution [1].

Moreover, the measurement of muscle in the human body has been used mainly for the purpose of assessing the nutritional status of the individual [2-4], as the muscle mass constitutes the body's principal reservoir of proteins.

Many different techniques have been used since the initiation of the first anthropometric studies. Analysis of body composition is based on different types of body partitioning, ranging from the traditional model, which considers that there are two body compartments, through multi-compartmental models. The first techniques used and intended to measure body fat are fundamentally anthropometry and hydro densitometry. The possibility of measuring the absorption of energy particles by tissues has given way to absorptiometry techniques; Currently, the advantages offered by dual energy X-ray absorptiometry (DXA) make it the most appropriate and widelyused technique, for measuring body composition in individuals of different ages and sexes [5].

This article shows in detail the three body compartments (bone, fat and muscle mass) in the Spanish Caucasian population, in both sexes and for each group by five-year age intervals from 0 to 15 years of age.

\section{SUBJECTS AND METHODS}

\subsection{Subjects}

For the purpose of this cross-sectional survey, we took a sample of the urban population of the Madrid Autonomous Region (Spain), comprised by 231 apparently healthy children, all Caucasians with a medium socioeconomic background, which we divided into 3 groups by five-year age intervals. Broken down by sex, there were 120 boys and 111 girls. Age range of the subjects was from 0 (birth) to 15 years. The study protocol was approved by the Office for Protection from Research Risks of Alcalá de Henares Medical School. The children were randomly selected among the volunteers who presented themselves for the study, who had previously 
been advised of it in a variety of schools. The inclusion criteria were the absence of any pathology (diabetes, liver disease, kidney disease, endocrine disease) or pharmacological treatment that could alter the metabolism. The children performed the compulsory exercises at their respective schools. The frequency of fitnessoriented physical education classes was three times every week for a 55-minute class period (older than 3 years of age). The subjects underwent a physical examination at time of the study to confirm a normal health status. Consent was obtained from each subject's parent or guardian after ethics information. Weight was measured using a calibrated scale and height was measured using a wall mounted stadiometer. Infants under 2 years of age were measured in supine position. Table 1 presents mean values for height, weight and BMI values for each age and gender group. None of the children was obese according to the WHO criteria.

\subsection{Densitometric Measures}

A total body scan was performed on each subject with a Norland XR-26 densitometer, software version 2.3 (Norland Co., Fort Atkinson, Wisconsin, USA. Emsor SA. Madrid). Each scan session was preceded by a calibration routine using multiple quality control phantoms that simulate bone and soft tissue. Scans were performed 3-4 hours post-pandrially. The children were placed in a supine position, and correctly centered on the exploration table. Infants were scanned when asleep. To begin the scan, the starting point was placed $1 \mathrm{~cm}$ directly above the centre of the patient's head. A baseline point was marked on the abdomen in an area of maximum soft tissue thickness. We selected the various body zones according to the equipment's specific software: on the body image, the upper axis of the thoracic cavity under the chin, the side axes on the scapular-humeral union, laterally adjusted between the upper limb and the trunk, and the lower axis at the caudal limit of the thoracic cavity. The upper axis of the pelvic cavity was placed on the iliac crest, with the lower axis below the pubic symphysis, ensuring that the lateral edges were over the femoral neck. The exploration as defined was completed in an average time of 15 minutes. Total radiation dose per in- dividual always remained below 5 mrem.

Body compartments calculations were performed for the following magnitudes:

$\mathrm{STM}=$ Soft Tissue Mass, in $\mathrm{g}$.

$\mathrm{BMC}=$ Bone Mineral Content, in $\mathrm{g}$.

TBM $=$ Total Body Mass $=$ TOTAL BMC + TOTAL

STM, in $\mathrm{g}$.

TSTM $=$ Total STM $=$ in $\mathrm{g}$.

LBM $=$ Lean Body Mass $=$ TSTM - FAT MASS, in g., where $90 \%$ its magnitude correspond to muscle mass.

$\mathrm{FM}($ fat mass $)=\mathrm{TBM}-(\mathrm{BMC}+\mathrm{LBM})$, in $\mathrm{g}$.

$\%$ FAT $=$ FAT MASS $* 100 /$ TBM.

For the fat mass the following variables were analyzed:

TBFM $=$ Total body fat mass.

$\%$ FAT $=$ Percentage body fat.

$\operatorname{TrFM}=$ Fat mass in trunk.

$\mathrm{AFM}=$ Fat mass in arms.

$\mathrm{LFM}=$ Fat mass in legs.

Ex FM $=$ Fat mass in extremities $=$ AFM + LFM.

Relation TrFM/ExFM

Relation TrFM/LFM

For the lean body mass the following variables were analyzed:

TLBM $=$ Total lean body mass.

TrLBM $=$ Lean body mass in trunk.

ALBM $=$ Lean body mass in arms

LLBM $=$ Lean body mass in legs.

For the bone tissue the following variables were analyzed:

TBMC: Total bone mineral content.

TrBMC: Trunk bone mineral content.

ABMC: Bone mineral content in arms.

LBMC: Bone mineral content in legs.

TBMC/H: TBMC-to-height ratio.

Because of the fact that BMC is defined as the mass of mineral contained in an entire bone or as the mass of mineral per unit bone length, bone mineral content is obviously a size-dependent parameter [6].

\subsection{Statistical Methods}

Statistical analyses were performed using the statistical and data management package SPSS for Windows,

Table 1. Anthropometric characteristics of the sample.

\begin{tabular}{ccccccccc}
\hline & \multicolumn{9}{c}{ Males } & \multicolumn{3}{c}{ Females } \\
\hline Age groups (years) & $n$ & Height $(\mathrm{cm})$ & Weight $(\mathrm{Kg})$ & BMI $(\mathrm{Kg} / \mathrm{m} 2)$ & $n$ & Height $(\mathrm{cm})$ & Weight $(\mathrm{Kg})$ & BMI(Kg/m2) \\
$1(0-5)$ & 19 & $101.7(16.6)$ & $17.0(5.4)$ & $16.0(2.1)$ & 19 & $98.9(25.7)$ & $14.0(4.6)$ & $16.5(3.3)$ \\
$2(6-10)$ & 45 & $134.6(12.2)$ & $32.2(8.8)$ & $17.5(2.7)$ & 36 & $134.7(9.9)$ & $31.2(7.6)$ & $16.9(2.4)$ \\
$3(11-15)$ & 56 & $162.6(16.1)$ & $52.4(13.8)$ & $19.4(2.2)$ & 56 & $158.9(10.3)$ & $50.0(10.5)$ & $19.6(2.8)$ \\
\hline
\end{tabular}

Values are means (standard deviation). BMI: Body mass index. 
Version 10.0. The results were expressed as the mean value (standard deviation) for each densitometric variable by gender and age group. The data were stratified by intervals of 5 years. Univariant variance analysis (ANOVA) was used to check the effect of gender on the densitometric variables considered. After calculating the TBMC-to-height ratio and introducing the necessary adjustments for weight gender differences of the mean values in each age group were tested for significance by means of Student's t-test. Multiple comparisons were made between the mean values of the variables for all the age groups using the Bonferroni test. The level of significance for all statistical tests of hypothesis was 0.05 .

\section{Results}

Table 1 shows the anthropometric characteristics of sample study and the differences in age- and genderspecific mean values for these magnitudes.

Age- and gender- specific means and SDs for TBFM, $\%$ FAT, TrFM/ExFM ratio and TrFM/LFM ratio are provided in Table 2.

In girls, \%FAT followed an evolutional pattern similar to that of TBFM. In boys, \%FAT increased to the age of 10 , decreased between the ages of 10 and 15 . There were significant gender differences in TBFM and \% FAT from the age of 11 to the age of 15 , while the mean values were always higher for girls. The TrFM/ExFM ratio showed significant gender-related differences from birth to the age of 10 . Mean values were higher in boys.
Age- and gender- specific means and SDs for TLBM, TrLBM, ALBM and LLBM are provided in Table 3. There were gender differences for TLBM in all age groups except for the 6-10 year age group. Values were in all cases higher for boys, with a high degree of signification $(\mathrm{p}<0.001)$, except for the $0-5$ year age group $(\mathrm{p}<0.05)$.

Age- and gender- specific means and SDs for TBMC, TrBMC, ABMC, LBMC and TBMC/H ratio are provided in Table 4. There is a significant TBMC increases, coinciding with the period of maximum skeletal growth. In all groups (0-15y), although TMBC values were higher in boys, we did not find any statistically significant differences between genders.

\section{Discussion}

Dual-energy X-ray absorptiometry scans is increasingly available and easily performed on children of all ages, making this method attractive for pediatric body composition measurement [7].

Changes with age in body composition begin at the moment of conception and ends only with the death; the changes between different phases of life are subtle and gradual. The age changes in human body composition have three phases: growth and development, maturity and senescence. The most important phase is growth and development and the variation in body composition in this period of life is a function of a complex interaction between genes, environment and behavior [8].

Table 2. Fat Mass.

\begin{tabular}{cccccccccc}
\hline \multirow{2}{*}{ Age groups (years) } & \multicolumn{2}{c}{ TBFM $(\mathrm{Kg})$} & \multicolumn{2}{c}{$\%$ TAT } & \multicolumn{2}{c}{ TrFM/ExFM ratio } & \multicolumn{2}{c}{ TrFM/LFM ratio } \\
\cline { 2 - 10 } & Boys & Girls & Boys & Girls & Boys & Girls & Boys & Girls \\
\hline $1(0-5)$ & $3.7(2.5)$ & $3.4(1.9)$ & $20.0(8.9)$ & $23.6(6.6)$ & $1.07(0.14)$ & $0.95(0.18)^{*}$ & $2.8(1.3)$ & $2.5(1.3)$ \\
$2(6-10)$ & $8.5(5.6)$ & $9.2(4.7)$ & $24.9(11.2)$ & $29.1(9.7)$ & $0.91(0.09)$ & $0.87(0.06)^{*}$ & $1.5(0.9)$ & $1.4(0.1)$ \\
$3(11-15)$ & $10.6(5.3)$ & $17.2(8.1)^{* * *}$ & $21.1(10.0)$ & $32.0(9.3)^{* * *}$ & $0.88(0.07)$ & $0.86(0.08)$ & $1.3(0.1)$ & $1.3(0.1)^{*}$ \\
\hline
\end{tabular}

Values are means (standard deviation) ${ }^{*} p \leq 0.05 * * * p \leq 0.001$. TBFM: Total body fat mass. $\%$ FAT = Percentage body fat. TrFM/ExFM ratio: Relation fat mass in trunk/fat mass in extremities. TrFM/LFM ratio: Relation fat mass in trunk / fat mass in legs.

Table 3. Lean Body Mass (Kg).

\begin{tabular}{cccccccccc}
\hline \multirow{2}{*}{$\begin{array}{c}\text { Age groups } \\
\text { (years) }\end{array}$} & \multicolumn{2}{c}{ TLBM } & \multicolumn{2}{c}{ TrLBM } & \multicolumn{3}{c}{ ALBM } & & \multicolumn{2}{c}{ LLBM } \\
\cline { 2 - 9 } & Boys & Girls & Boys & Girls & Boys & Girls & Boys & Girls \\
\hline $1(0-5)$ & $12.8(3.4)$ & $10.3(2.9)^{*}$ & $5.4(1.5)$ & $4.1(1.4)^{*}$ & $2.8(0.9)$ & $2.3(0.6)$ & $2.3(1.3)$ & $1.9(1.1)$ \\
$2(6-10)$ & $22.1(4.4)$ & $20.2(4.1)$ & $9.2(1.8)$ & $8.2(1.8)^{*}$ & $3.8(0.9)$ & $3.4(0.8)$ & $6.2(1.9)$ & $5.7(1.5)^{* * *}$ \\
$3(11-15)$ & $39.2(13.1)$ & $31.1(5.1)^{* * *}$ & $16.9(6.1)$ & $13.1(2.5)^{* * *}$ & $6.4(2.5)$ & $4.8(0.9)^{* * *}$ & $12.2(4.6)$ & $9.8(1.9)^{* * *}$ \\
\hline
\end{tabular}

Values are means (standard deviation) $* p \leq 0.05 * * * p \leq 0.001$. TLBM: Total lean body mass. TrLBM: Lean body mass in trunk. ALBM: Lean body mass in arms. LLBM: Lean body mass in legs. 
Table 4. Bone mineral content (g).

\begin{tabular}{cccccccccccc}
\hline Age groups & \multicolumn{9}{c}{ Boys } \\
\hline (years) & TBMC & TrBMC & ABMC & LBMC & TBMC/H ratio & TBMC & TrBMC & ABMC & LBMC & TBMC/H ratio \\
$1(0-5)$ & 579.59 & 190.46 & 86.14 & 77.17 & 5.49 & 456.03 & 149.95 & 68.41 & 65.34 & 4.56 \\
& $(214.5)$ & $(79.1)$ & $(46.2)$ & $(67.7)$ & $(1.48)$ & $(220.1)$ & $(78.0)$ & $(42.8)$ & $(60.2)$ & $(1.72)$ \\
\multirow{2}{*}{$2(6-10)$} & 1245.11 & 421.47 & 150.62 & 347.99 & 9.16 & 1214.27 & 410.49 & 137.26 & 366.47 & 8.92 & $(1.78)$ \\
& $(385.0)$ & $(154.1)$ & $(62.1)$ & $(159.2)$ & $(2.09)$ & $(313.8)$ & $(130.3)$ & $(43.0)$ & $(132.7)$ & \\
$3(11-15)$ & 2202.19 & 773.42 & 293.09 & 732.22 & 13.28 & 2261.71 & 839.54 & 274.65 & 744.09 & 14.08 \\
& $(719.1)$ & $(284.6)$ & $(148.4)$ & $(280.4)$ & $(3.07)$ & $(607.7)$ & $(271.0)$ & $(88.6)$ & $(220.4)$ & $(3.16)$ \\
\hline
\end{tabular}

Values are means (standard deviation). TBMC: Total bone mineral content. TrBMC: Trunk bone mineral content. ABMC: Bone mineral content in arms. LBMC: Bone mineral content in legs. TBMC/H: TBMC-to-height ratio.

\subsection{Fat Mass}

Fat mass is the most variable component of body composition, and between-individual variability ranges from approximately $6 \%$ to $60 \%$ of total body weight [9]. Many studies suggest there are three critical periods for the development of obesity and its complications. These include gestation and early infancy, the period of adiposity rebound that occurs between the ages of 5 and 7, and adolescence. The obesity that begins at these periods appears to increase the risk of persistent obesity and its complications. [10].

Our study of prepubertal children (ages 0 to 10) showed no gender-related differences in age-adjusted weight, height or BMI. Both \%FAT and the absolute mean values of total and regional fat mass increased progressively in both genders. Although no statistically significant gender-related differences were found, the values were usually higher in girls. In addition, girls had a significantly higher proportion of fat mass than of lean mass, and larger peripheral (extremities) fat deposits. The distribution of fat is an accepted criterion in the prediction of cardiovascular risk for both children and adults.

Koo et al. [11] found an increase in fat mass in girls was accompanied by a similar decrease in lean mass, which is consistent with our findings.

Subsequent studies to assess TBFM and muscle accumulation in prepubertal children using DXA yielded conflicting results. Some investigators observed no gender-related differences in body composition [12]. Others reported that girls had more fat and similar muscle mass [13-15]. Still others suggested that, compared with boys, girls had more fat but less muscle $[16,17]$. Our study showed that between the ages of 10 and 15 , boys experienced an increase in the proportion of muscle mass paired with a decrease in $\%$ fat. The divergences in these results are perhaps due to the effects of the different samples studied (age, geographical location, ethnicity, hormonal status, physical activity, lifestyle and so on).

\subsection{Lean Body Mass}

Henche et al [18] observed that the increase in lean mass of females is until age 15, from which age onwards it stabilises till 80 years of age. Apparently the muscular body component in females is subject to minimal variations during lifetime. Lean mass in males increases progressively until age 20 , then remains stable until age 55, after which it starts to decrease.

For TrLBM, there are differences by sex at all ages, which are, however, more pronounced from age 11 years onwards. The significant differences in regional lean mass occur at earlier age in legs than in arms.

Evaluation of muscular tissue with DXA is clearly supported in medical literature [19,20]. The study of body compartments in healthy subjects is extremely important, since the relationship between other body parts and muscle has been proven. For example the influence of muscular mass and fat mass on bone mass has been the focus of many research projects concluding that patients with smaller amounts of muscular and adipose tissues also have a smaller bone mass, bone mineral content and bone mineral density [21,22], as has been clearly evidenced in boys and girls during growing stages $[23,24]$.

The proportion of lean mass to total body mass is influenced by physical exercise or sports activity [25]. Additionally, constant physical activity increases the proportion of lean body mass and reduces the fat compartment, even without changes in body weight. In addition, in 11 years old children the positive influence of physical activity on bone size seems to be opposed by the tendency of physical activity to reduce fat mass. Therefore, exercise programs may be more effective at enhancing skeletal development in childhood when the exercise associate with a minimal reduction in fat mass [26]. 
Some investigators point that the age for gender differences for TLBM becomes evident at 7.5 years old only [27], others at age 10 [13] or 14 years of age.[28]. However, as reported in other studies, boys are generally more muscular than girls in all age groups [13]. In girls, the increase in lean mass we have shown occurs only until 15 years of age according to other authors [29].

\subsection{Bone Mass}

There is no evidence for gender differences in bone mass of either the axial or appendicular skeleton at birth. This absence of a substantial gender difference in bone mass is maintained until the onset of puberty [30], although there was some divergence in prepubescent boys between 6 and 11 [31].

TBMC does not present statistically significant differences between genders up to the age of 16 , as confirmed by other studies [32-34].

One study of healthy white Mediterranean Spanish children and adolescents, who were grouped according to age and gender in 1-y age groups, shows that L2-L4 bone mineral content values progressively increase from infancy to adulthood and mean values are similar in both genders until the age of 9-10 y, occurring with height. Thereafter, and corresponding to the more rapid height growth rate observed in girls because of earlier pubertal development, bone mineral content values are higher in girls than in boys until the age of 14-15 y [35]. These gender differences in this group of age may be hidden in our study because we have grouped the subjects per quinquennium of age, and the regions that we have studied have been different.

The marked increase demonstrated in bone mineral content in Caucasian children overlaps with that of Asians [36].

Several authors demonstrate that body composition in children can be improved by modifications of the school physical education curriculum, and consequently improving cardiovascular health [37]. Also, low bone mineral density, low physical activity and overweight in children of 3-10 years of age are potential risk factors for fracture of the distal forearm [38]. In the other hand, it is probable that children who experience a fracture are likely to be the children who do more physical activity and contact sports [39].

The reference data we present, can be used in clinical practice and in further research about children who practice some extracurricular sport or associated sport since some researchers have reported positive effects of physical activity on the bone mineral content of whole body [40], lumbar spine [41], and hip [42-44] in growing children, even though other authors are in disagree [45].

Some limitations of this study are the cross-sectional nature of the data and the inability to generalize the findings to other populations since the sample is restricted to an urban Spanish setting. On the other hand, our data are primarily based on chronological age, and thus do not account for the degree of sexual development.

\section{CONCLUSIONS}

Contrary to boys, girls showed from early infancy a smaller proportion of muscle mass and a higher proportion of body fat (from the age of 10), with fat deposits being mostly peripheral. There is no evidence for gender differences in bone mineral content in Caucasian children.

Therefore, the normal densitometric values presented offer useful information as a reference for comparison of populations of different genetic makeup and environmental influences. Similarly, densitometric values have proved to be useful for revealing the state of the skeleton during growth.

Dual-energy X-ray absorptiometry (DXA) makes it possible to detect differences in body compartments during the life cycle, as well as it shows clear differences between boys and girls.

\section{ACKNOWLEDGEMENTS}

We would like to thank for their time all the children and their families as well as all the teachers who took part in this study.

\section{REFERENCES}

[1] Goodpaster, B.H, and Kelley DE. Obesity and diabetes: Body composition determinants of insulin resistance. In: Human body composition. 2nd ed. 2005. Human Kinetics (eds), 365-375.

[2] Cañete A, Pérez-Serrano P, Polanco I. Estudio de los compartimentos corporales en la valoración del estado nutricional infantil. Exámenes complementarios. Pediátrika 1994; 14:42-47.

[3] Rodríguez G, Sarriá A, Fleta J, et al. Exploración del estado nutricional y composición corporal. An Esp Pediatr 1998; 48: 111-115.

[4] Takahashi N, Yuasa S, Fukunaga M, et al. Long-term evaluation of nutritional status using dual-energy $\mathrm{x}$-ray absorptiometry in chronic hemodialysis patients. Clin Nephrol 2003; 59: 373-378.

[5] Aguado Henche S and Gómez Pellico L. Body composition: evaluation methods. Eur J Anat 2005; 9 (2): 117-124.

[6] Schoenau E, Land C, Stabrey A et al. The bone mass concept: problems in short stature. Eur J Endocrinol 2004; 151: S87-91. doi:10.1530/eje.0.151S087

[7] Daniel P Williams, Pedro J Teixeira, Scout B Going. Exercise. Chapter 20. In: Human body composition. Steven B Heymsfield, Timothy G Lohman, ZiMian Wang, Scott B Going eds. Human kinetics. Second edition. USA. p 313-330. 2005.

[8] Richard N Baumgartner. Age. Chapter 17. In: Human 
body composition. Steven B Heymsfield, Timothy G Lohman, ZiMian Wang, Scott B Going eds. Human kinetics. Second edition. USA. p 259-269. 2005.

[9] Baumgartner RN. Age. In: Heymsfield SB, Lodman TG, Wang ZM, Going SB (eds) Human body composition. Human Kinetics: Champaign, IL; 2005. pp 256-270.

[10] Dietz WH. Critical periods in childhood for the development of obesity. Am J Clin Nutr; 1994; 59: 955-959.

[11] Koo WWK, Walters JC, Hockman EM. Body composition in infant at birth and postnatally. J Nutr 2000; 130 : 2188-2194.

[12] Cowell CT, Biody J, Llyd-Jones S, Smith C, Moore B, Howman-Giles R. Fat distribution in children and adolescents: the influence of sex and hormones. Horm Res 1997; 48:93-100. doi:10.1159/000191336

[13] Ogle GD, Allen JR, Humphries IR et al. Body-composition assessment by dual energy x-ray absorptiometry in subjects aged 4-26 y. Am J Clin Nutr 1995; 61: 746-753.

[14] Molgaard C, Fleischer Michaelen K. Changes in body composition during growth in healthy school-age children. Appl Radiat Isot 1998; 49: 577-579. doi:10.1016/S0969-8043(97)00076-6

[15] Johnson MS, Huang TT-K, Figueroa Colon R, Dwyer JH, Goran MI. Influence of leptin on changes in body fat during growth in African American and White children. Obes Res 2001; 9: 593-598. doi:10.1038/oby.2001.78

[16] Nagy TR, Gower BA; Trowbridge CHA; Dezenberg C; Shewchuk RM; Goran IM. Effects of gender, ethnicity, body composition, and fat distribution on serum leptin concentrations in children. J Clin Endocrinol Metab 1997; 82: 2148-2152. doi:10.1210/jc.82.7.2148

[17] Lindsay RS; Hanson RL; Roumain J; Ravussin E; Knowler WC; Tataranni PA (2001). Body mass index as a measure of adiposity in Children and adolescents: Relationship to adiposity by dual-energy x-ray absorptiometry and to cardiovascular risk factors. J Clin Endocrinol Metab; 86: 4061-4067. doi:10.1210/jc.86.9.4061

[18] Henche SA, Torres RR and Pellico LG. An evaluation of lean body mass in the Spanish population using X-ray absorptiometry (DXA). International Journal of Body Composition Research 2006; 4 (2):67-73.

[19] Kim J, Wang Z, Heymsfield SB et al. Total-body skeletal muscle mass: estimation by a new dual-energy X-ray absorptiometry method. Am J Clin Nutr 2002; 76(2): 378-383.

[20] Kim J, Heshka S, Gallagher D et al. Intermuscular adipose tissue-free skeletal muscle mass: estimation by dual-energy X-ray absorptiometry in adults. J Appl Physiol 2004; 97(2): 655-660. doi:10.1152/japplphysiol.00260.2004

[21] Khosla S, Atkinson EJ, Riggs BL et al. Relationship between body composition and bone mass in women. $\mathrm{J}$ Bone Miner Res 1996; 11:857-863. doi:10.1002/jbmr.5650110618

[22] Martín G, Valenti R, Ciovani S et al. Age-related changes in body composition of healthy and osteoporotic women. Maturitas 1997; 27: 25-33. doi:10.1016/S0378-5122(97)01108-0

[23] Courteix D, Lespessailles E, Loiseau-Peres S et al. Lean tissue mass is a better predictor of bone mineral content and density than body weight in prepubertal girls. Rev
Rhum Engl Ed. 1998; 65(5): 328-336.

[24] Vicente-Rodríguez G, Ara I, Pérez-Gómez J et al. Muscular development and physical activity as major determinants of femoral bone mass acquisition during growth Br J Sports Med 2005; 39(9): 611-616.

[25] Morante P, Gómez Pellico L, Calvillo JM, et al. Densitometría en baloncesto. Archivos de Medicina de Deporte 1992; 9: 79-84.

[26] Jon H Tobias, Colin D Steer, Calum G Mattocks, Chris Riddoch, Andy R Ness. Habitual levels of physical activity influence bone mass in 11-year-old children from the United-Kingdom: findings from a large population-based cohort. J Bone Miner Res 2007; 22(1): 101-109.

[27] Taylor A, Borleski J, Norman ME et al. Body composition and Bone Mineral Density: Normative Values for Children 2-9 years of Age. Pediatr Radiol 1995; 25: 676.

[28] Boot AM, Bouquet J, de Ridder AJ et al. Determinants of body composition measured by dual-energy $\mathrm{x}$-ray absorptiometry in Dutch children and adolescents. Am J Clin Nutr 1997; 66: 232-238.

[29] Van Der Sluis IM, De Ridder MA, Boot AM et al. Reference data for bone density and body composition measured with dual energy $x$ ray absorptiometry in white children and young adults. Arch Dis Child 2002; 87: 341-347. doi:10.1136/adc.87.4.341

[30] Bonjour JP, Rizzoli R. Bone acquisition in adolescence. In: Marcus R, Feldman D, Kelsey J, eds. Osteoporosis. San Diego, CA, Academic Press, 1996; 465-476.

[31] Horlick M, Thornton J, Wang J et al. Bone mineral in prepubertal children: gender and ethnicity. J Bone Miner Res. 2000; 15: 1393-1397. doi:10.1359/jbmr.2000.15.7.1393

[32] Faulkner RA, Bailey DA, Drinkwater DT et al. Regional and total body bone mineral content, bone mineral density, and total body tissue composition in children 8-16 years of age. Calcif Tissue Int. 1993; 53: 7-12. doi:10.1007/BF01352007

[33] Warner JT, Cowan FJ, Dunstan FDJ et al. Measured and predicted bone mineral content in healthy boys and girls aged 6-18 years: adjustment for body size and puberty. Acta Paediatr. 1998; 87: 244-249. doi:10.1111/j.1651-2227.1998.tb01432.x

[34] Aguado Henche S, Rodríguez Torres R, Clemente de Arriba $\mathrm{C}$ et al. Total and regional bone mineral content in healthy Spanish subjects by dual-energy X-ray absorptiometry. Skeletal Radiol 2008; 37 (11): 1025-1032. doi:10.1007/s00256-008-0519-3

[35] L del Río, Carrascosa A, Pons F, Gusinyé M, Yeste D, Domenech FM. Bone mineral density of the lumbar spine in white mediterranean spanish children and adolescents: changes related to age, sex, and puberty. Pediatr Res. 1994; 35: 362-366.

[36] Zhai F, Zhang L, Wang C, Pan H. Study of normal reference values for mineral contents in children and adolescents in Beijing. Wei Sheng Yan Jiu. 2004; 33: 172-175.

[37] Aaon L Carrel, Jennifer J McVean, R Randall Clark, Susan E Peterson, Jens C Eickhoff, David B Allen. Schoolbased exercise improves fitness, body composition, insulin sensitivity, and markers of inflammation in non-obese children. 2009; 22: 409-415.

[38] C Sierra Salinas, E Delangue Segura, J Blasco Alonso, VM Navas López, A Barco Gálvez. Disminución de la 
densidad mineral ósea y otros factores de riesgo en niños prepuberales con fractura del antebrazo distal 2009; 71(5): 383-390.

[39] Emma M Clark, Andy R Ness, Jon H Tobias. Vigorous physical activity increases fracure risk in children irrespective of bone mass: a prospective study of the independent risk factors for fractures in healthy children 2008 ; 23(7): 1012-1022.

[40] Bailey DA, McKay HA, Mirwald RL, Crocker PR, Faulkner RA. A six-year longitudinal study o the relationship of physical activity to bone mineral accrual in growing children: The university of Saskatchewan bone mineal accrual study. J Bone Miner Res 1999; 14: 16721679. doi:10.1359/jbmr.1999.14.10.1672

[41] Fuchs RK, Bauer JJ, Snow CM. Jumping improves hip and lumbar spine bone mass in prepubescent children: a randomized controlled trial. J Bone Miner Res 2001; 16: 148-156. doi:10.1359/jbmr.2001.16.1.148

[42] Fuchs RK, Snow CM. Gains in hip bone mass from high-impact training are maintained: A randomized controlled trial in children. J Pediatr 2002; 141: 357-362. doi:10.1067/mpd.2002.127275

[43] Petit MA, McKay HA, MacKelvie KJ, Heinonen A, Khan KM, Beck TJ. A randomized school-based jumping intervention confers site and maturity-specific benefits on bone structural properties in girls: A hip structural analysis study. J Bone Miner Res 2002; 17: 363-372. doi:10.1359/jbmr.2002.17.3.363

[44] Katherine Gunter, Adam DG Baxter-Jones, Robert L Mirwald, Hawley Almstedt, Robyn K Fuchs, Shantel Durski, Christine Snow. Impact exercise increases BMC during growth: An 8-year longitudinal study. J Bone Miner Res 2008; 23(7): 986-993.

[45] Gayani Alwis, Christian Linden, Susanna StaneviLundgren, Henrik G Ahlborg, Magnus Dencker, Jack Besjakov, Per Gardsell, Magnus K Karlsson. A schoolcurriculum-based exercise intervention program for two years in pre-pubertal girls does not influence hip structure. Dynamic Medicine 2008, 7: 8

doi: 10.1186/1476-5918-7-8.

http://www.dynamic-med.com/content/7/1/8. 